\title{
16. Improved but not necessarily safe: Water access and the Millennium Development Goals
}

\author{
Robert Bain \\ University of North Carolina at Chapel Hill, United States \\ Jim Wright \\ University of Southampton, United Kingdom \\ Hong Yang \\ University of Southampton, United Kingdom \\ Stephen Gundry \\ University of Bristol, United Kingdom \\ Steve Pedley \\ University of Surrey, United Kingdom \\ Jamie Bartram \\ University of North Carolina at Chapel Hill, United States
}

In early 2012 the United Nations announced that the drinking water target of the Millennium Development Goals (MDGs) had been reached in 2010: in two decades, and five years ahead of schedule, the proportion of people without sustainable access to safe drinking water had been halved (World Health Organization (WHO)/ United Nations Children's Fund (UNICEF) 2012a). Whilst this undoubtedly represents a major achievement, fundamental concerns regarding the monitoring of safe water have been gaining prominence (Harmon 2012).

The measure used to assess progress towards the MDG target is use of an improved source; these are water sources that were considered likely to provide safe drinking water (Table 1). Consequently, this approach is an assessment of specific types of water sources, rather than the quality of the water they provide. Improved sources do not always supply safe water due to 
the presence of microbial or chemical contamination. In order to explore the scale of this discrepancy and how it might be addressed in monitoring, the Joint Monitoring Programme (JMP) for Water Supply and Sanitation of WHO and UNICEF commissioned a number of nationally representative studies. These Rapid Assessment of Drinking-Water Quality (RADWQ) studies were conducted in Ethiopia, Jordan, Nicaragua, Nigeria and Tajikistan between 2004 and 2005.

\section{Table 1: The Joint Monitoring Programme (JMP) classification of source types into improved and unimproved}

\begin{tabular}{|l|l|}
\hline Source class & Types of source included \\
\hline $\begin{array}{l}\text { Unimproved drinking water } \\
\text { sources }\end{array}$ & $\begin{array}{l}\text { Unprotected dug well, unprotected spring, cart with small } \\
\text { tank/drum, surface water (river, dam, lake, pond, stream, } \\
\text { canal, irrigation channels), and bottled water. }\end{array}$ \\
\hline $\begin{array}{l}\text { Improved: Piped into } \\
\text { dwelling, plot, or yard }\end{array}$ & $\begin{array}{l}\text { Piped water connection located inside the user's dwelling, } \\
\text { plot, or yard. }\end{array}$ \\
\hline Improved: other sources & $\begin{array}{l}\text { Public taps or standpipes, tube wells or boreholes, protected } \\
\text { dug wells, protected springs, or rainwater collection. }\end{array}$ \\
\hline
\end{tabular}

Source: WHO/UNICEF 2012 b.

In recent work (Bain et al. 2012), we sought to determine how these data on water-source quality would affect assessments of progress towards the 2015 MDG target in these countries. We adjusted reported coverage estimates for the following water quality parameters: thermotolerant coliform bacteria, arsenic, fluoride and nitrates. Accounting for compliance with the WHO Guidelines for Drinking-Water Quality for these parameters substantially lowers estimates of 'safe' water use in four of the five countries (see Figure 1). In Ethiopia and Nigeria, the countries with the largest populations, the adjustment represents an additional 8.9 and 22 million people without safe water in 2008. Across the five countries, the adjustment reduces reported access by 32 million people a sizeable difference when compared to the 70 million that have begun to use improved water sources in these countries between 1990 and 2008.

The RADWQ studies show marked differences between countries, not only in the extent of the adjustment, but also in the likelihood of particular supply types being contaminated. Although there are some general trends in water quality between supply types, this is not consisent between countries. For example, in Nigeria boreholes were more likely to be compliant ( 86 per cent) than piped supplies (77 per cent), whereas in Ethiopia the reverse was the case (66 per cent versus 80 per cent respectively). As these data highlight, there remains a need for substantial improvement of 'improved sources'. 


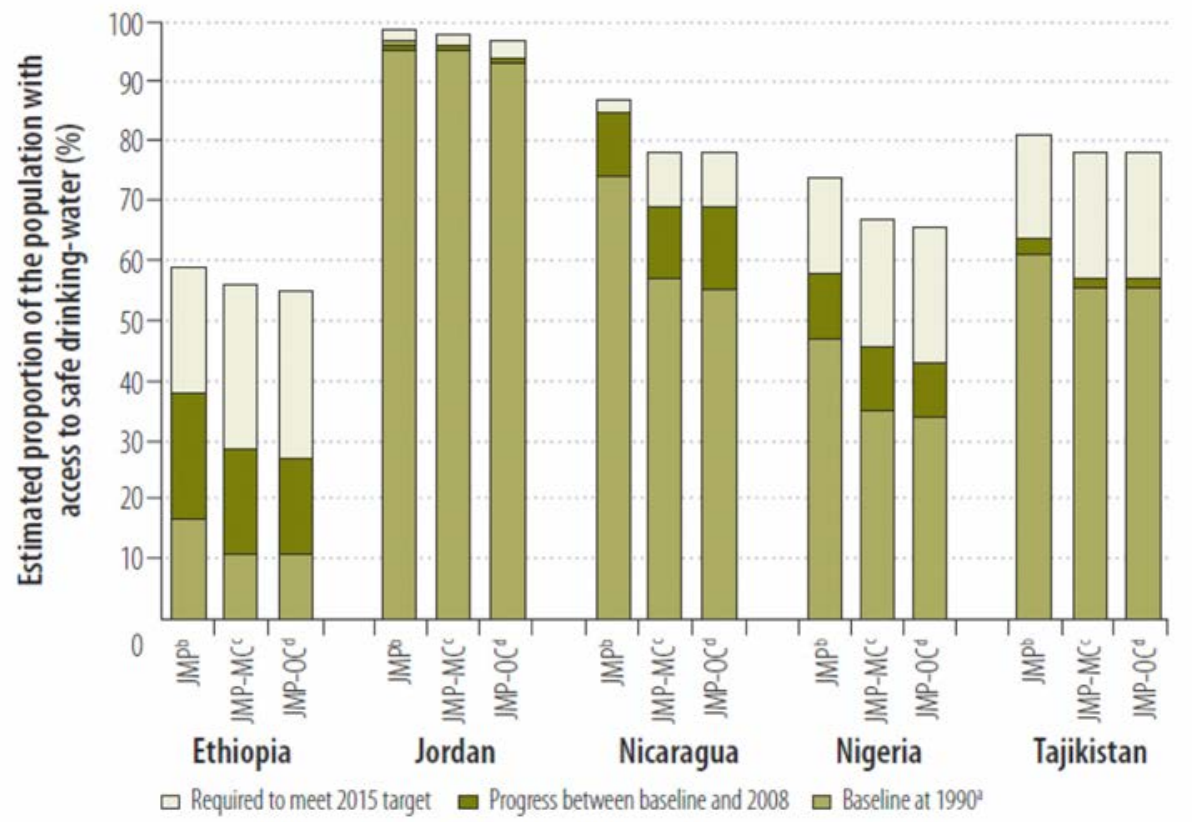

JMP, Joint Monitoring Programme for Water Supply and Sanitation; RADWQ Rapid Assessment of Drinking-Water Quality; WHO, World Health Organization.

' For Tajikistan, the baseline year was 1995.

- JMP: the percentage with access to safe drinking-water was estimated using the original JMP figures.

c JMP-MC: the percentage with access to safe drinking-water was estimated using the original JMP figures adjusted for the percentage microbial compliance (MC) with WHO guidelines on drinking-water contamination with thermotolerant coliform bacteria derived during the RADWQ project.

d JMP-OC: the percentage with access to safe drinking-water was estimated using the original JMP figures adjusted for the percentage overall compliance $(\mathrm{OC})$ with WHO guidelines on drinking-water contamination with thermotolerant coliforms, arsenic, fluoride and nitrates derived during the RADWQ project.

\section{Figure 1: Estimated percentage of the population using safe drinking water in 1990 and 2008 in five countries and the MDG target for 2015, by indicator}

Source: Bain et al. 2012. Reproduced with permission of the World Health Organisation (ID: 125807).

Studies in a number of other countries also highlight the discrepancy between improved water sources and the provision of water that is free of chemical and microbial contamination. For example, a preliminary study shows the Chinese population that gained access to safe water between 1990 and 2010 is at most 330 million, whereas 457 million people are reported by the JMP as having gained access to an improved source during the same period (Yang et al. 2012).

The compliance rate of improved sources is also known to vary considerably within countries; for example, between urban and rural areas or socio-economic 
groups. In related work (Yang et al. 2013) we combined data from the RADWQ studies with contemporary information from household surveys in the five countries to investigate socio-economic disparities in access to safe water. We found statistically significant differences in water quality between the poorest and richest households in Ethiopia, Nicaragua and Nigeria, even though we were unable to account for differential safety of sources of the same type. We also investigated differences in access to safe water by wealth quintile for users of the same type of supply using two household surveys that included measures of water quality. Whereas data from Bangladesh showed little difference in arsenic contamination between poor and rich borehole users, piped supplies used by the richest in Peru were considerably more likely to have adequate levels of chlorine residual ( $>0.1$ parts per million) than those used by the poorest. Although this provides only a partial and indirect indication of microbial contamination, the results are consistent with a more recent study in Peru (Miranda et al. 2010) that found the absence of an adequate chlorine residual to be more common in drinking water used by low-income households and in rural areas. The study also found similar patterns in the presence of total coliform or E. coli and provides compelling evidence of persistent disparities in water quality between urban and rural areas as well as income quintiles.

The magnitude of the problem globally has also been estimated. Given that nationally representative water quality data are only available through RADWQ for five countries, and that results vary greatly between countries, this exercise requires a range of assumptions and may be imprecise. When water quality is incorporated, however, global estimates of those without safe water range from 1.8 to 1.9 billion (Payen 2011; Onda et al. 2012; Wolf et al. 2013) - over a quarter of the 2010 world population and more than double the reported population not using improved sources.

The majority of the studies described above, including the RADWQ studies, have assessed water quality as the point of collection and have been based on sampling at a single timepoint rather than regular monitoring. They may not, therefore, reflect the quality of the water at the point of use; water quality can deteriorate due to handling practices during transport and storage, but may also be improved by treatment in the home (Wright et al. 2004). One-off sampling may overestimate yearlong safety since water quality can vary seasonally (Wright et al. 1986) and infrequent sampling may miss contamination events. Further research is required to understand how the safety of supplies varies throughout the year and what factors are the most important determinants of safety.

There is a great need to improve sector monitoring, including safety. Proposals prepared by expert working groups for the JMP recommend monitoring an 'intermediate' service level after the exprity of the MDGs (UNICEF/WHO 2013). The intermediate service level would include accessibility, continuity of 
supply as well as accounting for water safety (provisionally defined as $<10 \mathrm{E}$. coli per 100 millilitres throughout the year). This would represent a substantial improvement on the current practice of monitoring 'haves' and 'have nots' (Bartram 2008). There are, however, many challenges that need to be overcome, not least of which is establishing the feasibility and cost-effectiveness of water quality surveys in countries with limited data.

This work shows that interpretation of the MDG indicator as a surrogate for safe water can lead to substantial overestimates of the population using safe drinking water and, consequently, may also overestimate the progress made towards the 2015 MDG target. The current indicator does not adequately capture differences in safety between countries and does not reflect disparities in safety within countries. Whilst progress has been made, adjusting for water quality shows that much of the world's population still lacks access to safe water.

Robert Bain is a Visiting Scholar at the University of North Carolina at Chapel Hill. Professor Stephen Gundry directs the Water and Health Research Centre at the University of Bristol.

Dr Jim Wright is a Senior Lecturer at the University of Southampton.

Dr Hong Yang is a Postdoctoral Research Fellow also at University of Southampton, where he works on water pollution and aquatic environment change.

Dr Stephen Pedley is a Reader in the Division of Civil and Chemical Engineering, University of Surrey.

Professor Jamie Bartram is the Don and Jennifer Holzworth Distinguished Professor of Environmental Sciences and Engineering and Director of the Water Institute at the University of North Carolina at Chapel Hill. For more information please contact Robert Bain at rbain@email.unc.edu.

\section{References}

Bain, R.E.S., Gundry, S.W., Wright, J.A., Yang, H., Pedley, S., and Bartram, J.K., 2012. Accounting for water quality in monitoring access to safe drinking water as part of the Millennium Development Goals: lessons from five countries', Bulletin of the World Health Organization 90(3):228-35.

Bartram, J., 2008. 'Improving on haves and have-nots', Nature, 452:283-4.

Harmon, K., 2012. 'Improved but not always safe: despite global efforts, more than 1 billion people likely at risk for lack of clean water', Scientific American, 21 May. 
Miranda, M., Aramburu, A., Junco, J. and Campos, M. 2010. 'State of the quality of drinking water in households in children under five years in Peru, 2007-2010', Rev Peru Med Exp Salud Publica, 27(4):506-11.

Onda K., LoBuglio, J. and Bartram, J., 2012. 'Global access to safe water: accounting for water quality and the resulting impact on MDG progress', International Journal of Environmental Research and Public Health 9(3):880-94.

Payen, G., 2011. 'Worldwide needs for safe drinking water are underestimated: billions of people are impacted', originally published as: 'Le Droit à l'eau potable et à l'assainissement, Sa mise en œuvre en Europe', Académie de l'Eau, Smets et al., 2011:45-63.

United Nations Children's Fund (UNICEF)/ World Health Organization (WHO), 2013. Proposal for consolidated drinking water, sanitation and hygiene targets, indicators and definitions. Available at: http://www.wssinfo.org/ fileadmin/user_upload/resources/A-proposal-for-consolidated-WASH-goaltargets-definitions-and-indicators_version7_Nov22_final.pdf.

WHO/UNICEF, 2012a. 'Progress on sanitation and drinking water: 2012 update', World Health Organization Press, Geneva.

_ 2012b. 'Joint Monitoring Programme water and sanitation categories'. Available at: http://www.wssinfo.org/definitions-methods/watsan-categories/.

Wolf, J., Bonjour, S. and Prüss-Ustün, A., 2013. 'An exploration of multilevel modeling for estimating access to drinking water and sanitation', Journal of Water and Health 11(1):64-77.

Wright, J.A., Gundry, S.W. and Conroy, R., 2004. 'Household drinking water in developing countries: a systematic review of microbiological contamination between source and point-of-use', Tropical Medicine and International Health 9(1):106-17.

Yang, H., Wright, J.A. and Gundry, S.W., 2012. 'Water accessibility: boost water safety in rural China', Nature 484:318.

—_ Bain, R.E.S., Bartram, J.K., Gundry, S.W., Pedley, S. and Wright, J.A., 2013. 'Water safety and inequality in access to drinking-water between rich and poor households', Environmental Science \& Technology 47(3):1222-30. 
This text taken from Global Water: Issues and Insights by R. Quentin Grafton, Paul Wyrwoll, Chris White and David Allendes, published May 2014 by ANU Press, The Australian National University, Canberra, Australia. 